\title{
The Fly as Potential Vector in the Transmission of Leprosy
}

\author{
JOHN G. GEATER*
}

\begin{abstract}
In controlled experiments specimens of 3 genera of flies Musca, Calliphora and Stomoxys proved capable of taking up relatively large numbers of solid staining $A F B$ and globi from infected nasal mucus from untreated lepromatous patients and also from the surface of ulcerating highly infiltrated skin and nodules. Both Musca and Calliphora are capable of depositing these on distant surfaces. Bacilli can contaminate the mouthparts of Stomoxys after feeding on nasal mucus and ulcers, and this provides a possible means for direct inoculation of Myco. leprae. Flies may thus have an important role in the transmission of leprosy, the "infectious" patients from this angle being the one with positive nasal mucus or highly infiltrated and ulcerating skin. Every effort should be made to control flies in and around leprosy units.
\end{abstract}

\section{Introduction}

In considering the possible role of arthropods in the transmission of leprosy, attention has focussed on various types of biting arthropods (Dungal, 1960; Narayana et al., 1972). Before Mycobacterium leprae can be injected into a recipient they must first be ingested by the insect, and the source of such bacilli has been assumed to be either the few organisms which might adhere to the mouthparts during puncturing of the skin, or else bacilli circulating in the peripheral blood of lepromatous patients as demonstrated by Shankara Manja et al. (1972) and taken up with the blood feed. It would seem probable, however, that large numbers of bacilli would need to be taken up by any potential vector in order that it might by natural means transmit an infecting dose.

There is one group of insects, well known as potent spreaders of many infections, which is invariably and all too abundantly present wherever there is leprosy. This group comprises the several genera of flies, amongst which are the housefly (Musca), the bluebottle (Calliphora) and the biting stable fly (Stomoxys), all of which are known to spread a variety of infections owing to their habit of feeding on human and other excretia and mechanically transporting bacteria to food or onto wounds (even very minor breaks in the skin surface). Infection is transmitted mechanically by flies on their feet or by the excretion of ingested organisms in their faeces or in the drop of liquid that is regurgitated to moisten their food while feeding (Davey and Wilson, 1965). In addition, the biting Stomoxys could introduce bacteria into the skin whilst

- Previously: The Leprosy Mission, Mongar Hospital, East Bhutan.

Address for reprints: 78, Westwood Rd, B73 6UN, England.

Received for publication, 24 April, 1975. 
feeding, and it has been observed at this centre that infected fly-bites form a major cause of skin sepsis presenting in out-patients during that time of year when these flies abound.

Pedley $(1970,1973, a, b)$ showed that very considerable numbers of Myco. leprae were discharged from the noses of untreated lepromatous patients, and Davey and Rees (1974) showed these to be viable outside the body for 1.75 days, and even in one case for 7 days. Such nasal secretions could readily be ingested by flies or adhere to their feet, and would form a far more concentrated reservoir than bacteraemic blood or the relatively few bacilli which would be encountered during skin puncture. If it could be shown that Myco. leprae in sufficient numbers are carried by flies having fed on such sources, then the possibility must exist of organisms being implanted into broken skin surface by the insects or even injected into the skin if they are present on the mouthparts of Stomoxys.

Another major source of bacilli is the exudate from ulcerating nodules of some highly positive lepromatous patients.

The purpose of this work was to examine the possible uptake of Myco. leprae from these two sources by 3 representative flies-Musca, Stomoxys, and Calliphora-and also to examine whether Stomoxys can pick up bacilli when biting on intact skin. The question of whether flies actually transport bacilli from these sites to others was also examined.

\section{Method}

Flies of genera Musca, Stomoxys and Calliphora were captured away from the hospital. Numbers of each species were killed and the whole insect crushed and homogenized. The homogenate was stained for mycobacteria (decolourizing with acid alone) and a careful microscopical search carried out. This involved in each case a search of approximately 2000 fields before assessing them as negative.

Nasal mucus was obtained from untreated lepromatous patients. Specimens were copious, purulent and fluid, and exhibited large numbers of Myco. leprae. Within a month of starting treatment the nasal discharge became significantly less copious, had a lower bacterial load and was less readily ingested by flies.

Living flies were placed in separate large containers together with heavily bacillated nasal mucus smeared on a square of gauze. Granules of sugar were also placed in the container as an alternative food source for the flies. The flies were observed to feed voraciously upon the nasal mucus, generally prefering it to the cleaner food source. Often they placed their feet on the mucus whilst feeding.

After feeding on the mucus the flies were transferred to other containers. Some were killed and examined immediately. Others were kept alive for variable periods, being fed on syrup, before being killed and examined. The mouthparts and the legs were dissected from the flies and crushed into a small drop of saline to free any adherent bacilli. The gut contents were extruded and a smear made. Mouthparts, legs and gut contents were examined separately after staining for acid-fast bacilli (AFB). Although no AFB were found in any of the control flies, it is possible that a few saprophytic mycobacteria could be present on occasional flies, and to exclude this possibility decolourization was carried out subsequently with acid-alcohol. 

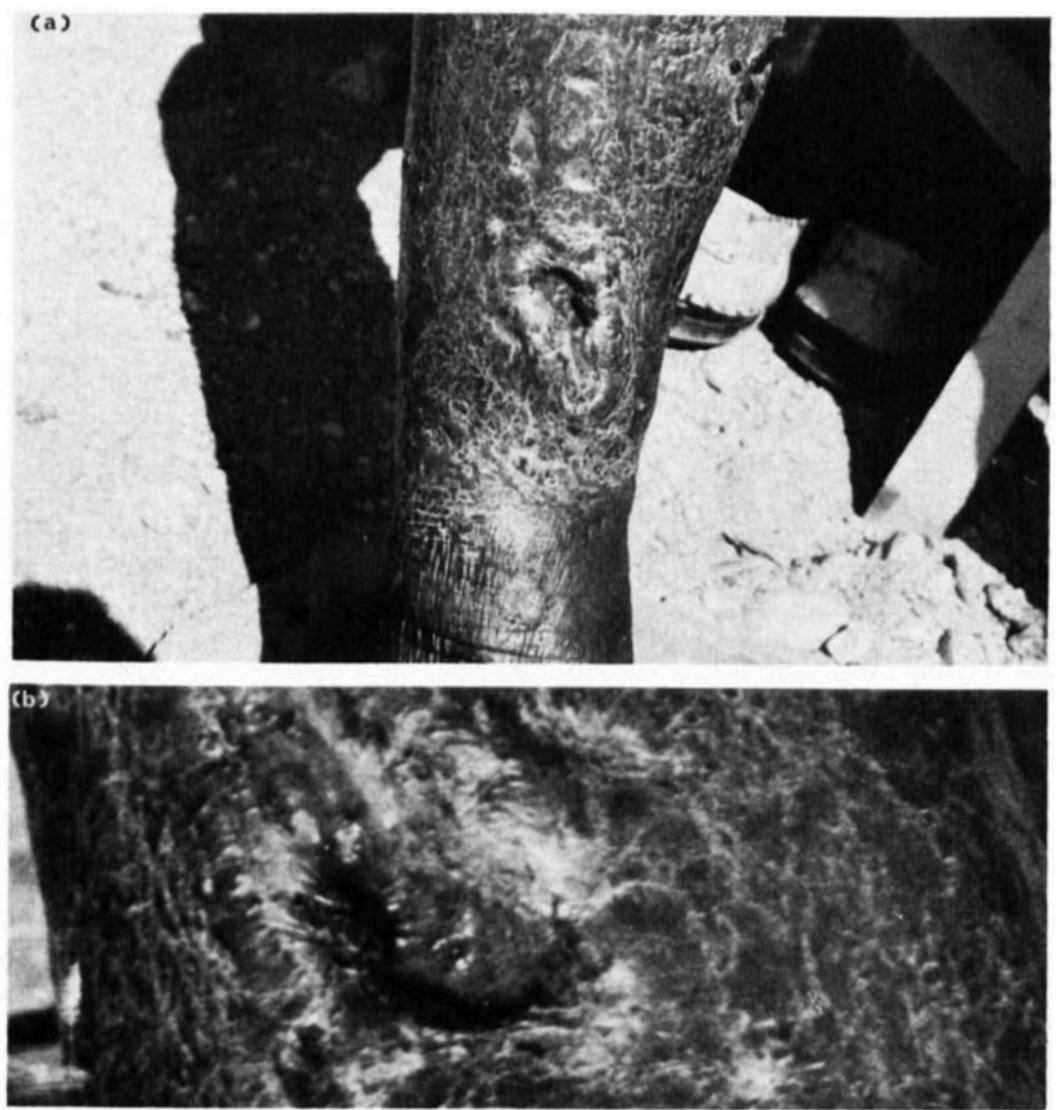

Fig. 1. Fly feeding on lepromatous ulcer. This fly was killed after $10 \mathrm{~min}$ and found to have solid staining AFB on legs, in the mouthparts and in the gut, 15 globi being counted in the gut and 3 in the mouthparts along with 20 individual bacilli.

In order to investigate the uptake of bacilli from ulcers and skin, flies were placed in containers over areas of skin of lepromatous patients including ulcerating nodules, and in the case of Stomoxys over areas of intact skin. They were left in position until the flies had been observed feeding, which in general they did readily. To reduce the artificial element in this work, certain of the flies which spontaneously alighted and fed on the ulcers were killed and examined

\section{Results}

No AFB were found in any of the control flies of the three representative genera chosen-Musca, Stomoxys or Calliphora.

\section{(a) UPTAKE FROM MUCUS FEEDING}

Results are tabulated in Table 1. All flies of the three genera examined within one hour of feeding were found to have taken up bacilli from the nasal 
TABLE 1

Uptake of acid/alcohol-fast mycobacteria by flies fed on nasal mucus from untreated lepromatous patients

\begin{tabular}{|c|c|c|c|c|c|c|c|c|c|c|c|c|c|c|}
\hline \multirow{3}{*}{$\begin{array}{l}\text { Fly } \\
\text { Genera }\end{array}$} & \multirow{3}{*}{$\begin{array}{l}\text { Time of } \\
\text { examination } \\
\text { after feed }\end{array}$} & \multirow{3}{*}{$\begin{array}{l}\text { Total number } \\
\text { of flies }\end{array}$} & \multicolumn{12}{|c|}{ Number of positive flies: presence of globi } \\
\hline & & & \multicolumn{4}{|c|}{ Legs } & \multicolumn{4}{|c|}{ Mouth } & \multicolumn{4}{|c|}{ Abdomen } \\
\hline & & & + & $\mathrm{S}$ & $\mathrm{S}+$ & $\widehat{\text { Globi }}$ & $\mp$ & $\mathrm{S}$ & $\mathrm{S}+$ & Globi & $\mp$ & $\mathrm{S}$ & St & $\overline{\text { Globi }}$ \\
\hline Musca & $1 \mathrm{~h}$ & 13 & 10 & 6 & 4 & 50 & 9 & 8 & 1 & 1 & 12 & 6 & 6 & 27 \\
\hline Musca & 1 day & 8 & 1 & 1 & $=$ & & 3 & 3 & - & & 8 & 3 & 5 & 62 \\
\hline Musca & 2 days & 2 & 0 & - & - & & 1 & 1 & - & & 1 & 1 & $=$ & \\
\hline Musca & 3 days & 3 & 0 & $=$ & - & & 0 & - & - & & 3 & 2 & 1 & 8 \\
\hline Stomoxys & $1 \mathrm{~h}$ & 6 & 3 & 3 & - & & 4 & 3 & 1 & 1 & 5 & 3 & 2 & 3 \\
\hline Stomoxys & 1 day & 2 & 0 & - & $=$ & & 0 & - & - & & 2 & 1 & 1 & 2 \\
\hline Calliphora & $1 \mathrm{~h}$ & 3 & 2 & $=$ & 2 & 7 & 2 & 1 & 1 & 7 & 2 & $=$ & 2 & 25 \\
\hline Calliphora & 1 day & 2 & 0 & $=$ & $=$ & & 0 & - & - & & 1 & 1 & - & \\
\hline Calliphora & 3 days & 2 & 0 & - & - & & 0 & - & - & & 2 & 2 & - & 2 (small) \\
\hline $\begin{array}{l}\text { Total no. of } \\
\text { flies examined }\end{array}$ & & 41 & & & & & & & & & & & & \\
\hline
\end{tabular}

+ No. of flies with AFB present.

S No. of flies with less than 20 solid staining bacilli present.

S+ No. of flies with more than 20 solid staining bacilli present.

Globi Total no. of globi counted in positive groups. 
mucus onto some part of their bodies. The majority of bacilli were to be found in the contents of the gut, sometimes in very large numbers. For instance, in one Musca acid/alcohol-fast bacilli were present in almost all the 500 microscope fields examined of smears of intestinal contents, as well as 31 globi.

Musca. Twelve of the 13 Musca killed within one hour of feeding had solid staining bacilli in their intestinal contents, 6 of them having globi present. Bacilli were also found on the mouthparts of 9 of the 13 flies and on the legs of 10,4 of these having globi present and one having as many as 41 globi, although some of these were small.

Solid staining bacilli persisted in the gut for 3 days. At 24 hours they were present, often in large numbers, in the guts of all 8 flies examined. Thereafter there was a rapid diminution in. numbers, one of the two flies killed after $48 \mathrm{~h}$ had a few bacilli, and whilst all 3 flies examined at $72 \mathrm{~h}$ did have bacilli in the gut, only 3 solid staining bacilli were detected in one and 6 in the other. The third, however, still contained 8 globi.

Bacilli were still present on the legs of one and in the mouthparts of 3 of the 8 flies examined at $24 \mathrm{~h}$. They were also present in the mouthparts of one fly after $48 \mathrm{~h}$.

Stomoxys. Being a small fly, as might be expected, fewer bacilli were to be found after feeding. Even so, all but one of the 8 examined were found to have taken up bacilli from the nasal mucus, and 3 of them contained globi, one after $24 \mathrm{~h}$. If these flies are potentially to inject $M y c o$. leprae into the skin, the numbers of bacilli found in mouthparts are important. Solid staining bacilli were found in the mouthparts of 4 out of 6 Stomoxys flies tested immediately after a meal of nasal mucus. One globus was found.

Calliphora. Results obtained with bluebottles closely approximated to those obtained with the large numbers of Musca. Two of the 3 examined shortly after feeding contained very large numbers of bacilli, especially in their intestinal contents. Two had bacilli on their mouthparts one with 7 globi. Globi were also found on the feet of 2 of the 3 . More globi and solid bacilli were found on the feet and mouthparts of these 2 bluebottles than on the equivalent sites of Musca or Stomoxys. Excretion of bacilli from the gut appeared to proceed rapidly, although small globi were still detectable in the guts of the two Calliphora examined after 3 days.

\section{(b) UPTAKE FROM THE SKIN}

No bacilli were found in any Stomoxys feeding on the intact skin of mild lepromatous volunteers (BI between 2 and 3). In the case of 6 Stomoxys placed on the earlobes of a highly lepromatous patient (BI 5.2), solid staining bacilli were found in the intestines of 4 flies after biting. Numbers of solid staining bacilli were low, a total of 20 in the 4 positive flies, with a maximum of 9 in any one fly. No bacilli were found in the mouthparts of the flies tested.

The uptake of bacilli by Stomoxys feeding on ulcerated skin was greater, and solid staining bacilli were detected on the mouthparts of 3 out of 5 flies. There were 25 solid staining mycobacteria present on the mouthparts of one fly. All 5 of each Musca and Calliphora which were killed after feeding on ulcerating skin of the highly bacilliferous volunteer were found to contain bacilli, and these were present on all 3 parts examined-legs, mouthparts and abdomen. The 
number of globi taken up seemed to be lower than the uptake from nasal mucus, but one Musca was found with 15 globi in its intestinal contents and 3 on its mouthparts. This fly happened to be one which had spontaneously alighted to feed on the ulcer and was killed at the conclusion of the meal.

\section{Do Flies Transmit Mycobacterium leprae?}

Having shown that flies of the 3 genera studied can take up AFB, the question remains that if they are to be considered vectors they must be shown to carry the bacteria from the source to a receptor surface, and there deposit the bacteria. In order to demonstrate this, microscope slides coated with albumin were placed at one end of a large container and a small quantity of nasal mucus was placed at the other end. A few grains of sugar were placed on the slides, and pairs of Musca or Calliphora admitted to the containers.

The flies fed readily on the nasal mucus and frequently also on the sugar grains, alternating between the two over the course of 1 or $2 \mathrm{~h}$, at the end of which time the slides were removed and stained. Of the 10 slides examined, only one showed no AFB. Globi were present on 6 of the 10 slides, and 2 of the slides, both of which were in a container with 2 Calliphora for a $2 \mathrm{~h}$ period had solid staining bacilli, and of ten globi, in virtually every part of the slide examined.

\section{Discussion}

The acid-fast bacilli in the nasal mucus of untreated lepromatous patients have been shown to be Myco. leprae capable of inducing infection in the mouse foot-pad (Davey and Rees, 1974). Whilst some 300 different species of acid-fast bacilli are known, the number which retain stain when decolourized with acid-alcohol is small and includes Myco. leprae. This fact, the absence of any mycobacteria in the controls, and the demonstration of globi in a large number of the flies examined after feeding on nasal mucus or ulcer exudate from lepromatous patients suggests that at least a large number of the bacilli demonstrated were $M y c o$. leprae. Of these a great number were solid staining, suggesting viability, but confirmation of this must await the results of mouse foot-pad inoculations.

In view of the known methods of spread of bacteria by flies-on the feet, in the faeces and in the "vomit drop" secreted during the course of feeding, and in the case of Stomoxys by contamination of the mouthparts-the finding of solid staining $M y c o$. leprae in relatively large numbers on feet, mouthparts and in the gut of flies would suggest that all these mechanisms could play a role in the transfer of viable organisms from nasal mucus or the ulcerating skin of a highly lepromatous patient to a suitable receptor area.

It is one thing to demonstrate that an arthropod fortuitously takes bacilli into its body when feeding and something quite different to claim it as a vector. A vector must also be shown to release the bacilli in a viable form to receptor tissues. Whilst we have not thus far fully complied with this condition, the finding of solid staining bacilli and globi on the albumin coated slides on which Musca and Calliphora had been feeding, shows that mechanical transfer can occur, and it is possible that the same mechanism could operate when a fly feeds on a defect in the skin of a hitherto uninfected person. Nor would this 
be a purely passive or random chance as the flies are positively attracted to any defect of skin surface, which would thus seem to provide a potential site for the lodgement and possible later multiplication of bacilli.

Whilst the intact epidermis would not seem to provide a portal of entry for Myco. leprae, implantation of bacilli into breaks of the skin surface could allow entry of them into the dermis or even provide for haematogenous spread. The demonstration of contamination of the mouthparts of Stomoxys after feeding on nasal mucus or ulcer suggests that direct inoculation by this means is possible.

Uptake of bacilli was undoubtedly greatest in all 3 species tested after feeding on infected nasal mucus. Feeding on ulcerating highly infiltrated or nodular skin also provided many bacilli. It is likely that other genera of flies of similar feeding habits (e.g. Fannia, Lucilia) would give similar results. Of less importance would seem to be the uptake of bacilli in the blood meal of Stomoxys biting intact skin of even highly positive patients with bacteraemia, because of the small number of Myco. leprae in blood compared with the large number on nasal mucus or ulcer exudate. The patient with a lower BI would not seem to pose a significant risk.

\section{Conclusions}

Whilst full confirmation of these findings awaits the results of mouse foot-pad experiments, it has been shown that:

1. Flies of several genera are capable of taking up relatively large numbers of solid staining Myco. leprae from infected nasal mucus and the surface of ulcerating highly infiltrated skin or nodules.

2. Both Musca and to a greater extent Calliphora are capable of depositing these on distant surfaces.

3. Bacilli can contaminate the mouthparts of Stomoxys after feeding on mucus or ulcers, and this provides a possible means for direct inoculation of Myco. leprae.

4. In view of the above, the "infectious patient" with regard to possible transmission by flies, is the one with positive nasal mucus or highly infiltrated and ulcerating skin.

5. Every effort should be made to control flies in and around leprosy units in order to reduce the possible risk of transportation of leprosy bacilli to the surrounding population, as well as for obvious reasons of general hygiene.

\section{Acknowledgements}

My thanks go to Mr S. Yogi and Mr S. Rongong for patient and painstaking technical assistance, and to the several patients of Mongar Hospital who gave their help with forbearance and good humour. Also to Dr Cecil Pedley for his encouragement.

\section{References}

Davey, T. F. and Rees, R. J. W. (1974). The nasal discharge in leprosy: clinical and bacteriological aspects. Lep. Rev. 45, 121.

Davey, T. H. and Wilson, T. (1965). Control of disease in the tropics. H. K. Lewis \& Co. p. 348.

Dungal, X. (1960). Is leprosy transmitted by insects. Lepr: Rev. 31, 25. 
Narayanan, E., Shankara Manja, K., Bedi, B. M. S., Kircheimer, W. F. and Balusubrahmanyan, M. (1972). Arthropod feeding experiments in lepromatous leprosy. Lepr. Rev. 43, 188.

Pedley, J. C. (1970). Composite skin smears. Lepr. Rev. 41, 31.

Pedley, J. C. (1973a). The nasal mucus in leprosy. Lepr. Rev. 44, 33.

Pedley, J. C. (1973b). The Nasal Mucus in Leprosy. Abstracts of Tenth International Leprosy Congress, Bergen, p. 29.

Shankara Manja, K., Bedi, B. M. S., Kasturi, G., Kircheimer, W. F. and Balusubrahmanyan, M. (1972). Demonstration of Myco. leprae in the peripheral blood of leprosy patients. Lepr. Rev. 43, 181 . 